\title{
Dietary inflammatory index and risk of oesophageal cancer in Xinjiang Uyghur Autonomous Region, China
}

\author{
Li Tang $^{1 *}$, Nitin Shivappa ${ }^{2,3,4}$, James R. Hebert ${ }^{2,3,4}$, Andy H. Lee ${ }^{5}$, Fenglian $\mathrm{Xu}^{6}$ and Colin W. Binns ${ }^{5}$ \\ ${ }^{1}$ Chinese Evidence-based Medicine Center, West China Hospital, Sichuan University, Chengdu 610041, People's \\ Republic of China \\ ${ }^{2}$ Cancer Prevention and Control Program, University of South Carolina, Columbia, SC 29208, USA \\ ${ }^{3}$ Department of Epidemiology and Biostatistics, Arnold School of Public Health, University of South Carolina, Columbia, \\ SC 29208, USA \\ ${ }^{4}$ Connecting Health Innovations LLC, Columbia, SC 29201, USA \\ ${ }^{5}$ School of Public Health, Curtin University, Perth, WA 6845, Australia \\ ${ }^{6}$ Faculty of Health, University of Technology Sydney, Sydney, NSW 2007, Australia
}

(Submitted 26 September 2017 - Final revision received 31 December 2017 - Accepted 24 January 2018 - First published online 5 March 2018 )

\section{Abstract}

Diet has been shown to have an effect on both inflammation and oesophageal cancer. This study investigated the association between the dietary inflammatory index $\left(\mathrm{DII}^{\circledR}\right)$ and the risk of oesophageal cancer in Xinjiang Uyghur Autonomous Region, China. A case-control study was conducted during 2008-2009 in Urumqi and Shihezi. DII scores were calculated based on dietary intake assessed by a validated FFQ administered to 359 incident oesophageal cancer patients and 380 hospital-based controls. Higher DII scores indicate more pro-inflammatory diets. Logistic regression analyses were performed to assess the association between DII scores and oesophageal cancer risk. Oesophageal cancer patients had a significantly higher median DII score $(-0 \cdot 35$; interquartile range $(\mathrm{IQR})=-2 \cdot 25$, $1 \cdot 86)$ than that of controls $(-1 \cdot 41$; IQR $-3 \cdot 07,0 \cdot 40)$. Multivariable logistic analysis revealed a positive association between higher DII scores and oesophageal cancer risk $\left(\mathrm{OR}_{\text {Quartile } 4 v .1} 2 \cdot 55 ; 95 \% \mathrm{CI} 1 \cdot 61,4 \cdot 06 ; P_{\text {trend }}<0 \cdot 001\right)$. A pro-inflammatory diet appears to be associated with an increased risk of oesophageal cancer in Xinjiang Uyghur Autonomous Region. Specific carcinogenic mechanisms are discussed. Accumulating evidence, to which the study contributes, indicates that encouraging the intake of more anti-inflammatory foods may be a strategy to protect against oesophageal cancer in this high-risk area of China.

\section{Keywords: Dietary inflammatory index: Oesophageal cancer: China: Xinjiang}

Oesophageal cancer has the eighth highest incidence of all cancers worldwide, with 455800 new cases and 400200 deaths estimated to have occurred in $2012^{(1)}$. Incidence rates of oesophageal cancer vary considerably across different geographic regions $^{(2)}$, highlighting the potential role of nutritional and lifestyle factors in oesophageal cancer aetiology. Because of the lack of early clinical symptoms, oesophageal cancer is typically diagnosed at an advanced stage. Prognoses for these patients remain very poor, with a 5-year survival rate of $<20 \%{ }^{(3)}$. Therefore, primary prevention of oesophageal cancer is a major public health priority.

There are two histological types of oesophageal cancer squamous cell carcinoma and adenocarcinoma. Although squamous cell cancers are thought to be more strongly associated with tobacco exposure ${ }^{(4,5)}$, both types have been found to be associated with diet-related inflammation based on the dietary inflammatory index $\left(\mathrm{DII}^{\circledR}\right)^{(6)}$. On the basis of recent data collected from the Chinese National Central Cancer Registry, oesophageal squamous cell cancer (ESCC) was the most common type, being responsible for nearly $90 \%$ of the cases of oesophageal carcinoma in China ${ }^{(7)}$. It has been well established that tobacco smoking and alcohol drinking are important risk factors for $\operatorname{ESCC}^{(8)}$. A diet high in processed meat and frequent drinking of very hot beverages may also increase the risk of developing ESCC. The major aetiological factors for oesophageal adenocarcinoma (EAC) are gastro-oesophageal reflux and body fatness (as indicated by increased BMI, waist circumference and waist:hip ratio). There is some evidence that low intake of fruits and vegetables is linked to an increased risk of both ESCC and $\mathrm{EAC}^{(9)}$.

Chronic inflammation is a state of continuous presence of inflammatory cytokines in circulation and in the tissues, and has

Abbreviations: DII, dietary inflammatory index; EAC, oesophageal adenocarcinoma; ESCC, oesophageal squamous cell cancer.

* Corresponding author: Dr L. Tang, fax +8628 8542 3040, email: tangli207@hotmail.com 
been shown to play a crucial role in the development of various epithelial cancers ${ }^{(10,11)}$. In particular, it has been shown that chronic inflammation is an important risk factor in the development of oesophageal cancer, especially epithelial damage involved in $\operatorname{ESCC}^{(12,13)}$.

Dietary habits represent modifiable factors that have been shown to influence both inflammation ${ }^{(14-17)}$ and oesophageal cancer $^{(18-20)}$. Diet represents a complex set of exposures that often interact, and has a cumulative effect on both inflammatory responses and health outcomes. The DII was developed to assess the inflammatory potential of an individual's diet ${ }^{(21)}$. A pro-inflammatory diet is characterised by a high consumption of foods rich in SFA and carbohydrates, and a low consumption of foods rich in fibre, PUFA, flavonoids and other antioxidant dietary components. The DII has been validated in a variety of longitudinal and cross-sectional studies with various inflammatory markers, including C-reactive protein $(\mathrm{CRP})^{(22)}$, IL-6 ${ }^{(23)}$ and TNF- $\alpha^{(24)}$. The DII has been associated with the risk of colorectal cancer in case-control studies in Spain and Italy ${ }^{(25,26)}$, in three cohort studies from the USA ${ }^{(27-29)}$ and risk of various cancers in case-control studies in Italy $^{(30-33)}$. Specifically related to oesophageal cancer, the DII has been shown to be associated with oesophageal cancer in Italy, Iran, Sweden and Ireland $^{(6,24,31,34)}$.

Xinjiang Uyghur Autonomous Region, located in the northwest of China, is one of the areas constituting the 'Asian oesophageal cancer belt ${ }^{\text {(35) }}$. The objective of the present study was to investigate whether pro-inflammatory diets, as measured by the DII, are associated with increased risk of oesophageal cancer among adults residing in this remote region of China. This is the first study to examine this association in China.

\section{Methods}

\section{Study design and participants}

A hospital-based case-control study of oesophageal cancer was conducted in Urumqi and Shihezi, Xinjiang Uyghur Autonomous Region of China, between January 2008 and December 2009. Participants were recruited from the Xinjiang Tumor Hospital, Shihezi People's Hospital, Kuitong Hospital and No. 1 Affiliated Hospital of Shihezi University. Medical records and pathology reports were reviewed to identify patients with histopathologically confirmed incident oesophageal cancer that had been diagnosed within the previous 12 months. Pathological diagnoses were based on the International Classification of Disease for Oncology (ICD-O-3 codes: C150-C155, C158, C159) ${ }^{(36)}$. Patients without histopathologically confirmed oesophageal cancer and those with reported memory problems were excluded. Of the total 364 incident eligible patients identified, 359 consented to participate.

During the same period, controls were recruited from inpatient wards of the Departments of Ophthalmology, Orthopaedics, Respiratory Diseases and Physiotherapy at the same hospitals. Exclusion criteria for controls were previous diagnosis of a malignant disease, on long-term medical diet and self-reported memory problems. Random numbers were generated using the software Research Randomizer (http://www.socialpsychology.org) to make a final selection whenever more controls were available than could be interviewed. Of the 400 eligible controls who were frequencymatched to cases on sex and age ( \pm 5 years), 380 eventually gave their consent to participate in the study (with a response rate of $95 \%)$. No significant differences were found in demographic variables (age, education and marital status) between participants and non-participants in both case and control groups.

Given the sample size of 359 case patients and 380 control participants and a two-sided statistical significance level of $0 \cdot 05$, our study achieved more than $99 \%$ power to detect a 2-fold increased risk of oesophageal cancer associated with pro-inflammatory diets ${ }^{(31)}$. For this power calculation, the prevalence of consuming a pro-inflammatory diet was estimated at 40 and $25 \%$ in the cancer patients and control group, respectively.

The study protocol was approved by the participating hospitals and the Human Research Ethics Committee of Curtin University (approved no. HR 56/2006). Written informed consent was obtained from all participants, who were assured of confidentiality of the information provided and their right to withdraw at any time without prejudice.

\section{Interview and exposure measurements}

All participants were interviewed in-person by trained nurses, usually in the presence of their next-of-kin, to facilitate the recall of dietary habits ${ }^{(37)}$. The nurses were aware of the case-control status of the participants, but remained blind to the study hypothesis. The structured questionnaire composed sections on demographic characteristics, anthropometry, personal health and family medical histories, diet and lifestyle, including cigarette smoking and alcohol drinking. A 137-item semi-quantitative FFQ, which had been validated and included fruits, vegetables, meat, poultry, cereals and beverages commonly consumed in Northwestern China, was used to collect dietary information ${ }^{(38)}$. Frequency and quantity of intake were recorded in detail. The reference recall period for dietary variables was set at 5 years before diagnosis for cases and 5 years before interview for controls. Participants who consumed at least $500 \mathrm{ml}$ of alcoholic beverages per week were classified as 'often'; otherwise, they were referred to as 'never/seldom' drinkers.

Daily intakes of carbohydrate, protein, cholesterol, fat, SFA, fibre, niacin, folic acid, thiamin, riboflavin, vitamin $\mathrm{C}$, vitamin $\mathrm{E}$, vitamin $\mathrm{B}_{6}, \beta$-carotene, $\mathrm{Fe}, \mathrm{Mg}$ and $\mathrm{Zn}$ were estimated based on the frequency and amounts of each food or beverage item consumed using the Chinese Food Composition Tables ${ }^{(39)}$. The US Department of Agriculture nutrient database ${ }^{(40)}$ was used for the conversion to vitamin $\mathrm{B}_{12}$, MUFA, $n-3, n-6$, PUFA and SFA, as such values were unavailable from the Chinese Food Composition Tables.

\section{Calculation of dietary inflammatory index scores}

The development ${ }^{(17)}$ and validation ${ }^{(22)}$ of the DII has been explained elsewhere. Through evaluation of peer-reviewed literature published from 1950 to 2010, the score is based on 1943 articles linked to forty-five individual nutrient, food or flavonoid intake parameters. Points were assigned to each of 
these parameters according to whether they increased $(+1)$, decreased $(-1)$ or had no (0) effect on six established inflammatory biomarkers: IL-1b, IL- 4 , IL-6, IL-10, TNF- $\alpha$ and CRP. The score for each of the food parameters was weighted according to the study designs and total number of research articles. Overall parameter-specific inflammatory effect scores were then calculated based on the ratio of the total weighted number of articles:the weighted pro- and anti-inflammatory articles for each parameter followed by subtracting the antiinflammatory fraction from the pro-inflammatory fraction. Parameters that had a robust pool of literature, that is greater than the median number of 236 weighted articles, were assigned the full value of that score. Parameters with a number of weighted articles $<236$ were adjusted according to the distance of their number from this median.

Actual dietary intake data from the FFQ were adjusted against a reference global daily mean and standard deviation intake for each parameter to obtain a $z$ score. The global intake data were based on consumption data from eleven countries in different parts of the world. To reduce the effect of skewness, a common occurrence in dietary data, $z$ scores were converted to proportions. These, in turn, were centred on zero by doubling the proportion and subtracting 1 . The centred proportion for each intake parameter was multiplied by its respective parameterspecific inflammatory effect score. All of the food-parameterspecific DII scores were then summed to create the overall DII score for each participant in the study, DII $=b_{1} \times n_{1}+b_{2} \times n^{2}+$ $\ldots+b_{22} \times n_{22}$, where $b_{\mathrm{i}}(i=1, \ldots, 23)$ refers to the literaturederived inflammatory effect scores for each of the evaluable food parameters and $n_{\mathrm{i}}$ refers to the food-parameter-specific centred percentiles, which were computed from the FFQderived dietary data. The steps involved in DII calculation are shown in Fig. 1. For the current study, data on twenty-three of the forty-five DII food parameters could be derived from the FFQ and were thus used for calculating the DII scores. These include energy, carbohydrate, protein, fat, SFA, iron, cholesterol, fibre, PUFA, $n-3, n-6$, niacin, thiamin, riboflavin, $\mathrm{Mg}, \mathrm{Zn}$, vitamin $\mathrm{C}$, vitamin $\mathrm{E}$, vitamin $\mathrm{B}_{6}, \mathrm{~B}_{12}, \beta$-carotene, garlic and onions. Alcohol intake was not included in the DII calculation because daily consumption information was not recorded. All of these food-parameter-specific DII scores are then summed to create the overall DII score for each subject in the study.

\section{Statistical analysis}

The DII score was categorised into quartiles with cut-off points based on the control distribution. The $\chi^{2}$ test was used for categorical variables. Either the Student's $t$ test or the MannWhitney $U$ test was used for continuous variables to compare the sample characteristics and DII scores between case and control groups. $\chi^{2}$ and one-way ANOVA tests were next conducted to test four differences in participant characteristics across quartiles of the DII score by case and control status.

Unconditional logistic regression analyses were then performed to ascertain the association between DII score and the oesophageal cancer risk, with the lowest level of DII score being the reference category. Potential confounding variables considered were age (years), sex, education level (none/ primary, secondary, tertiary), BMI ( 5 years ago, $\mathrm{kg} / \mathrm{m}^{2}$ ), total energy intake $(\mathrm{kJ} / \mathrm{d}(\mathrm{kcal} / \mathrm{d})$ ), smoking status (never, ever), alcohol drinking (never/seldom, often) and family history of cancer in first-degree relatives (no, yes). These variables were either established or plausible risk factors based on findings in the peer-reviewed literature. All of the variables were included in the multivariable logistic regression model.

In addition to reporting crude and adjusted OR and corresponding $95 \% \mathrm{CI}$, dose-response relationships were assessed by tests for linear trend. All statistical analyses were performed using the SPSS $^{\circledR}$ package version 22 (IBM Corp.).

\section{Results}

Table 1 compares characteristics and DII scores of the sample by case-control status. The case and control participants were, on average, 61.0 (SD 11.4) years old with a mean BMI of $24 \cdot 1$ (sD 3.7$) \mathrm{kg} / \mathrm{m}^{2}$. Approximately, $72 \%$ of cases were male, $54 \%$ smoked and $46 \%$ regularly drank alcoholic beverages. Compared with the controls, patients with oesophageal cancer tended to belong to an ethnic minority group (as compared with the Han majority), have lower education level and have a family history of oesophageal cancer. DII scores in this study ranged from -4.72 (most anti-inflammatory score) to $4 \cdot 18$ (most pro-inflammatory score). The median DII score among oesophageal cancer patients $(-0 \cdot 35$, interquartile range (IQR) $-2 \cdot 25,1 \cdot 86)$ was significantly higher than that of their control counterparts $(-1 \cdot 41$, IQR $-3 \cdot 07,0 \cdot 40)$.

Study characteristics across quartiles of DII are provided in Table 2. Participants who consumed more pro-inflammatory diets (i.e. with higher DII scores) were older, more likely to belong to a minority ethnic group (as opposed to Han) and to smoke.

The results of logistic regression analyses are shown in Table 3. A higher DII score (indicating a more proinflammatory diet) was associated with an increased risk of oesophageal cancer, with a significant dose-response relationship $\left(P_{\text {trend }}<0 \cdot 001\right)$. The adjusted OR was 2.55 (95\% CI 1.61 , 4.06) for participants in the highest quartile of DII scores compared with those in the lowest quartile. Belonging to an ethnic minority group (adjusted OR 1·86; 95\% CI 1·24, 2·80), having a family history of oesophageal cancer (adjusted OR $2.74 ; 95 \%$ CI 1.60, 4.66), an education level lower than secondary school (adjusted OR 1.82; $95 \%$ CI 1.09, 3.06) and smoking (adjusted OR 1.59; 95\% CI 1.07, 2.36) also were significantly and independently associated with an elevated risk of oesophageal cancer. None of their interactions with DII was found to be significant.

\section{Discussion}

Findings from this case-control study in Northwestern China suggest that consuming a more pro-inflammatory diet, as evidenced by higher DII scores, is associated with an increased risk of oesophageal cancer. This is the first study in China to explore the association between DII scores and oesophageal cancer. Our findings are generally in line with the results obtained from a population-based case-control study from Sweden, in which the 
Review of articles published from 1950 to 2010 resulting in 1943 studies linking a total of 45 food parameters with inflammatory biomarkers

A score for each food parameter was calculated giving:

+1 to each article if the effects were pro-inflammatory (significantly increased IL-1 $\beta$, IL-6, TNF- $\alpha$ or CRP, or decreased IL-4 or IL-10),

-1 if the effects were anti-inflammatory (significantly decreased IL-1 $\beta$, IL-6, TNF- $\alpha$ or CRP, or increased IL-4 or IL-10),

0 if the food parameter did not produce any significant change in inflammation

The score for each food parameter was weighted according to the study design. The weights were 10 (experimental design), 8 (observational), 7 (case-control), 6 (crosssectional), 5 (experimental with animals), 3 (cell culture)

A food parameter-specific overall inflammatory effect score was calculated by substracting the anti-inflammatory fraction from the pro-inflammatory fraction. This score was corrected if the total weighted number of articles was $<236$. In these cases the raw overall inflammatory score is multiplied by the total weighted number of articles divided by 236

$z$-score and centred-percentiles for each of the 23 food parameters for each participant of this study were calculated based on the average and standard deviation for each food parameter obtained from the global database which was created from the consumption of the original 45 food parameters fron 11 countries from around the world

2 food parameters were not available in this study

The centred percentile for each food parameter was multiplied by the the respective 'overall food parameter-specific inflammatory effect score' to obtain the 'food parameterspecific Dll score'

All of the 'food parameter-specific DII scores' are summed to create the 'overall DII score' for each individual

Fig. 1. Sequence of steps in creating the dietary inflammatory index (DII) in the Chinese oesophageal cancer case-control study. CRP, C-reactive protein.

significant associations with DII were observed for oesophageal squamous cell carcinoma (OR $\mathrm{OR}_{\text {Qurtile } 4 v .1} 4 \cdot 35 ; 95 \%$ CI 2.24, 8.43),

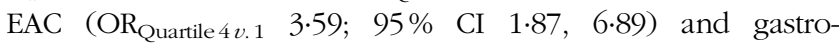
oesophageal junctional adenocarcinoma $\left(\mathrm{OR}_{\mathrm{Quartile}} 4 \mathrm{v} \cdot 1\right.$ 2.04; $95 \%$ CI 1.24, 3.36). Significant trends across quartiles of DII were observed for all oesophageal cancer subtypes ${ }^{(6)}$. Results from the current study also are consistent with those of two previous studies undertaken in $\operatorname{Iran}^{(24)}$ and Italy ${ }^{(31)}$, both of which showed that a pro-inflammatory diet is associated with a higher risk of oesophageal squamous cell carcinoma. In addition to these studies $\left(\mathrm{OR}_{\mathrm{dii}}>1 \cdot 20 v . \leq 1 \cdot 20=8 \cdot 24 ; \quad 95 \%\right.$ CI $2 \cdot 03, \quad 33.47$ and $\mathrm{OR}_{\text {quartile } 5 v .1} 2 \cdot 46 ; 95 \%$ CI $1.40,4 \cdot 36 ; P_{\text {trend }}<0 \cdot 001$, respectively), the DII also has been shown to be associated with increased odds of reflux oesophagitis (OR 1.87; $95 \%$ CI $0.93,3.73$ ), significantly increased odds of Barrett's oesophagus (OR 2.05; $95 \%$

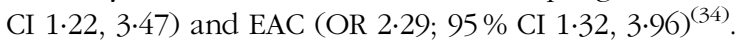

One of the possible mechanisms behind the observed positive association between the DII and oesophageal cancer may be mediated by increasing levels of pro-inflammatory cytokines such as vascular endothelial growth factor, CRP and IL-8. These cytokines form an important component of the oesophageal tumour micro-environment. As such, they play a key role in cancer development, growth and progression ${ }^{(41)}$ through various processes including promoting proliferation, inducing 
Table 1. Comparison of participant characteristics and dietary inflammatory index between case and control groups, Xinjiang, China, January 2008-December 2009

(Numbers and percentages; mean values and standard deviations; medians and interquartile ranges (IQR))

\begin{tabular}{|c|c|c|c|c|c|}
\hline \multirow[b]{2}{*}{ Variables } & \multicolumn{2}{|c|}{ Cases } & \multicolumn{2}{|c|}{ Controls } & \multirow[b]{2}{*}{$P^{*}$} \\
\hline & $n$ & $\%$ & $n$ & $\%$ & \\
\hline \multicolumn{5}{|l|}{ Sex } & 0.62 \\
\hline Male & 260 & $72 \cdot 4$ & 269 & $70 \cdot 8$ & \\
\hline Female & 99 & $27 \cdot 6$ & 111 & $29 \cdot 2$ & \\
\hline \multicolumn{3}{|l|}{ Ethnic group } & \multicolumn{2}{|c|}{0.001} & \\
\hline Han & 270 & $75 \cdot 2$ & 322 & 84.7 & \\
\hline Minority & 89 & 24.8 & 58 & $15 \cdot 3$ & \\
\hline \multicolumn{5}{|l|}{ Education level } & $<0.001$ \\
\hline None/primary & 183 & $51 \cdot 0$ & 136 & $35 \cdot 8$ & \\
\hline Secondary & 140 & 39.0 & 191 & $50 \cdot 3$ & \\
\hline Tertiary & 36 & $10 \cdot 0$ & 53 & $13 \cdot 9$ & \\
\hline \multicolumn{5}{|l|}{ Smoking status } & 0.19 \\
\hline Never & 164 & 45.7 & 192 & $50 \cdot 5$ & \\
\hline Ever & 195 & $54 \cdot 3$ & 188 & 49.5 & \\
\hline \multicolumn{5}{|l|}{ Alcohol drinking } & 0.22 \\
\hline Never/seldom & 193 & 53.8 & 187 & $49 \cdot 2$ & \\
\hline Often & 166 & $46 \cdot 2$ & 193 & $50 \cdot 8$ & \\
\hline \multicolumn{5}{|l|}{$\begin{array}{l}\text { Family history of cancer } \\
\text { in first-degree relatives }\end{array}$} & $<0.001$ \\
\hline No & 306 & $85 \cdot 2$ & 356 & 93.7 & \\
\hline Yes & 53 & $14 \cdot 8$ & 24 & $6 \cdot 3$ & \\
\hline \multicolumn{5}{|l|}{ Age at interview (years) } & 0.34 \\
\hline Mean & \multicolumn{2}{|c|}{$61 \cdot 4$} & \multicolumn{2}{|c|}{$60 \cdot 6$} & \\
\hline SD & \multirow{2}{*}{\multicolumn{2}{|c|}{11.0}} & \multicolumn{2}{|c|}{11.8} & \\
\hline \multicolumn{3}{|l|}{ BMI (5 years ago, $\mathrm{kg} / \mathrm{m}^{2}$ ) } & & & 0.18 \\
\hline Mean & \multirow{2}{*}{\multicolumn{2}{|c|}{$\begin{array}{c}24 \cdot 3 \\
3.8\end{array}$}} & \multicolumn{2}{|c|}{$\begin{array}{c}24.0 \\
3.6\end{array}$} & \\
\hline SD & & & & & \\
\hline \multicolumn{5}{|l|}{ Energy intake $(\mathrm{kJ} / \mathrm{d})$} & 0.047 \\
\hline Mean & \multicolumn{2}{|c|}{$18031 \cdot 8$} & \multicolumn{2}{|c|}{$19700 \cdot 6$} & \\
\hline SD & \multicolumn{2}{|c|}{$11216 \cdot 0$} & \multicolumn{2}{|c|}{$11361 \cdot 7$} & \\
\hline Energy intake (kcal/d) & & & & & 0.047 \\
\hline Mean & \multirow{2}{*}{\multicolumn{2}{|c|}{$\begin{array}{l}4309 \cdot 7 \\
2680 \cdot 7\end{array}$}} & \multicolumn{2}{|c|}{$4708 \cdot 5$} & \\
\hline SD & & & & & \\
\hline \multicolumn{5}{|l|}{ Dietary inflammatory index } & $<0.001$ \\
\hline Median & \multirow{2}{*}{\multicolumn{2}{|c|}{$\begin{array}{c}-0.35 \\
-2.25,1.86\end{array}$}} & - & 41 & \\
\hline IQR & & & -3 & 0.40 & \\
\hline
\end{tabular}

${ }^{*} X^{2}$, Student's $t$ test or Mann-Whitney $U$ test for difference between cases and controls.

angiogenesis and by inhibiting the recruitment of immune cells to the tumour site ${ }^{(42)}$. Hypoxia, a common state of low $\mathrm{O}_{2}$ levels in inflamed tissues, causes DNA damage and induces tumorigenic factors that further result in progression of cancer ${ }^{(42)}$. Inflammation also alters the extracellular matrix and provides structural support to developing tumours ${ }^{(42)}$. Resveratrol, which is an important component of grapes, has been found to be a natural cyclo-oxygenase-2 (COX-2) inhibitor that is involved in the antiinflammatory pathway ${ }^{(43)}$. Another phytochemical, curcumin, which is present in large quantities in turmeric, can down-regulate inflammation, and has been demonstrated to be capable of preventing activation of a pro-inflammatory chemical $-\mathrm{NF}-\kappa \mathrm{B}^{(44)}$. $n-3$ Fatty acids, which are abundant in marine fish that are fairly rarely eaten in this population, can stimulate anti-inflammatory signalling molecules that have been associated with oesophageal cancer protection $^{(45)}$.

This study adds to the body of research that clearly indicates a role of diet-associated inflammation in oesophageal carcinogenesis. Unlike the effect of tobacco, which appears to be stronger for squamous cell cancers ${ }^{(4,5)}$, the effect of diet appears to affect both histopathologic subtypes ${ }^{(34,46-48)}$. This finding is reinforced by findings from our study in Sweden ${ }^{(6)}$, which found nearly identical increased odds of 4.35 and 3.59, respectively, for ESCC and EAC.

Some mechanisms may manifest irrespective of specific histopathological type. For example, both CRP and certain interleukins such as IL-6 appear to affect both ESCC and $\mathrm{EAC}^{(49)}$. These cytokines regulate processes associated with inflammation that occur along carcinogenic pathways that appear to be operative irrespective of histopathological subtype. Both histopathologic subtypes are well known to be associated with inflammation. The effect of chronic inflammation in the growth of ESCC is well-established ${ }^{(31,50-52)}$. Similarly, the influence of inflammation in the process of malignant transformation in the sequence from Barrett's oesophagus to frank adenocarcinoma is particularly well defined ${ }^{(53-55)}$, including the effect of oxidative stress, which is intimately associated with both diet and inflammatory response, in relation to reflux oesophagitis ${ }^{(56)}$.

Some exposures, such as consuming beverages at very high temperatures, will logically affect the proximal oesophagus, where most ESCC occur ${ }^{(57)}$. In addition, within China some putative environmental causes have been suggested to affect ESCC in particular ${ }^{(58)}$.

Certain processes are emerging for specific cancer subtypes. However, the specificity of the effect is hard to determine given the infancy of the field. For example, the Janus kinase/signal transducer and activator of transcription 3 (JAK/STAT3) may play a unique role in ESCC by encouraging cross talk between $\mathrm{NF}-\kappa \mathrm{B}$ and COX-2, which are well known to link inflammation to tumorigenesis. Blocking the JAK/STAT3 pathway in ESCC cell lines appears to regulate cell growth and inhibit angiogenesis ${ }^{(59)}$. With the rapid rise of EAC, there also has been an interest in sorting out inflammation-related pathways for this cancer. These include local immune response, tissue microenvironment, metabolic profile, intracellular signalling and microRNA $^{(12)}$. Given the current state of knowledge, there is nothing compelling the view that these mechanisms are exclusive to a particular histopathological type of tumour. For example, although dysregulation of cytokines in ESCC is known and members of VEGF family may play an important role in ESCC $^{(60)}$, this same process may apply to EAC. Similarly, while the effect of the diet on the microbiome has been investigated in $\mathrm{EAC}^{(61)}$, these effects may not be specific to histology of the cancer. However, it must be borne in mind that adenocarcinomas occur in the distal oesophagus where the influence of microbiome could be different from that in the proximal oesophagus. This potential lack of specificity may help to put in perspective the results of this Chinese study in which it is not been possible to distinguish subtype (although there are many more squamous cell cancers than adenocarcinomas in this population).

Limitations of this study include the retrospective nature of the case-control design. Although exposure information was collected with an instruction to report on exposures in the past, true temporal sequence cannot be established with certainty. This limits inferences regarding the causal relationship between 
Table 2. Participant characteristics across quartiles (Q) of dietary inflammatory index (DII) among all participants, Xinjiang, China, January 2008-December 2009

(Numbers and percentages; mean values and standard deviations)

\begin{tabular}{|c|c|c|c|c|c|c|c|c|c|}
\hline \multirow[b]{2}{*}{ Characteristics } & \multicolumn{2}{|c|}{$\begin{array}{c}\text { Q1 }(<-3.067) \\
(n \text { 149) }\end{array}$} & \multicolumn{2}{|c|}{$\begin{array}{c}\text { Q2 (-3.067 to }-1.462) \\
(n 169)\end{array}$} & \multicolumn{2}{|c|}{$\begin{array}{c}\text { Q3 }(-1.461 \text { to } 0.334) \\
(n 181)\end{array}$} & \multicolumn{2}{|c|}{$\begin{array}{c}\text { Q4 }(\geq 0.335) \\
(n 240)\end{array}$} & \multirow[b]{2}{*}{$P^{*}$} \\
\hline & $n$ & $\%$ & $n$ & $\%$ & $n$ & $\%$ & $n$ & $\%$ & \\
\hline \multicolumn{9}{|l|}{ Sex } & 0.36 \\
\hline Male & 112 & $75 \cdot 2$ & 123 & $72 \cdot 8$ & 132 & $72 \cdot 9$ & 162 & 67.5 & \\
\hline Female & 37 & 24.8 & 46 & $27 \cdot 2$ & 49 & $27 \cdot 1$ & 78 & 32.5 & \\
\hline \multicolumn{9}{|l|}{ Ethnic group } & 0.002 \\
\hline Han & 135 & $90 \cdot 6$ & 133 & 78.7 & 134 & 74.0 & 190 & $79 \cdot 2$ & \\
\hline Minority & 14 & $9 \cdot 4$ & 36 & $21 \cdot 3$ & 47 & $26 \cdot 0$ & 50 & $20 \cdot 8$ & \\
\hline \multicolumn{9}{|l|}{ Education level } & 0.11 \\
\hline None/primary & 57 & 38.3 & 69 & $40 \cdot 8$ & 71 & 39.2 & 122 & $50 \cdot 8$ & \\
\hline Secondary & 75 & $50 \cdot 3$ & 75 & 44.4 & 89 & $49 \cdot 2$ & 92 & 38.3 & \\
\hline Tertiary & 17 & 11.4 & 25 & $14 \cdot 8$ & 21 & $11 \cdot 6$ & 26 & $10 \cdot 8$ & \\
\hline \multicolumn{9}{|l|}{ Smoking status } & 0.08 \\
\hline Never & 58 & 38.9 & 82 & 48.5 & 92 & $50 \cdot 8$ & 124 & $51 \cdot 7$ & \\
\hline Ever & 91 & $61 \cdot 1$ & 87 & $51 \cdot 5$ & 89 & $49 \cdot 2$ & 116 & $48 \cdot 3$ & \\
\hline \multicolumn{9}{|l|}{ Alcohol drinking } & 0.19 \\
\hline Never/seldom & 74 & 49.7 & 78 & $46 \cdot 2$ & 92 & $50 \cdot 8$ & 136 & $56 \cdot 7$ & \\
\hline Often & 75 & $50 \cdot 3$ & 91 & 53.8 & 89 & $49 \cdot 2$ & 104 & 43.3 & \\
\hline \multicolumn{9}{|l|}{ Family history of cancer in first-degree relatives } & 0.11 \\
\hline No & 127 & $85 \cdot 2$ & 150 & 88.8 & 144 & 79.6 & 205 & 85.4 & \\
\hline Yes & 22 & $14 \cdot 8$ & 19 & $11 \cdot 2$ & 37 & 20.4 & 35 & 14.6 & \\
\hline \multicolumn{9}{|l|}{ Age at interview (years) } & 0.25 \\
\hline Mean & \multicolumn{2}{|c|}{$61 \cdot 3$} & \multicolumn{2}{|c|}{$59 \cdot 8$} & \multicolumn{2}{|c|}{$62 \cdot 2$} & \multicolumn{2}{|c|}{$60 \cdot 8$} & \\
\hline SD & \multicolumn{2}{|c|}{11.8} & \multicolumn{2}{|c|}{$11 \cdot 2$} & \multicolumn{2}{|c|}{$11 \cdot 2$} & \multicolumn{2}{|c|}{11.5} & \\
\hline $\mathrm{BMI}\left(\mathrm{kg} / \mathrm{m}^{2}\right)$ & \multirow{3}{*}{\multicolumn{2}{|c|}{$\begin{array}{c}22.3 \\
3.8\end{array}$}} & \multirow{3}{*}{\multicolumn{2}{|c|}{$\begin{array}{c}22 \cdot 3 \\
3 \cdot 6\end{array}$}} & & & & & 0.69 \\
\hline Mean & & & & & & & \multirow{2}{*}{\multicolumn{2}{|c|}{$\begin{array}{c}22 \cdot 3 \\
3 \cdot 6\end{array}$}} & \\
\hline SD & & & & & & & & & \\
\hline
\end{tabular}

${ }^{*} x^{2}$ Test or one-way ANOVA for difference among quartiles of DII.

Table 3. Oesophageal cancer risk for dietary inflammatory index in Xinjiang, China, January 2008-December 2009

(Numbers and percentages; odds ratios and $95 \%$ confidence intervals)

\begin{tabular}{|c|c|c|c|c|c|c|c|c|c|}
\hline \multirow[b]{2}{*}{ Dietary inflammatory index } & \multicolumn{2}{|c|}{ Cases } & \multicolumn{2}{|c|}{ Controls } & \multicolumn{2}{|c|}{ Crude } & \multicolumn{2}{|c|}{ Adjusted } & \multirow[b]{2}{*}{$P_{\text {for trend }}{ }^{*}$} \\
\hline & $n$ & $\%$ & $n$ & $\%$ & OR & $95 \% \mathrm{Cl}$ & $\mathrm{OR}^{*}$ & $95 \% \mathrm{Cl}$ & \\
\hline All participants ( $n$ 739) & & & & & & & & & $<0.001$ \\
\hline Q1 $(<-3.067)$ & 54 & $15 \cdot 0$ & 95 & $25 \cdot 0$ & & & & & \\
\hline Q2 $(-3.067$ to -1.462$)$ & 74 & $20 \cdot 6$ & 95 & $25 \cdot 0$ & 1.37 & $0.87,2.15$ & 1.39 & $0.86,2.23$ & \\
\hline Q3 $(-1.461$ to 0.334$)$ & 86 & 24.0 & 95 & $25 \cdot 0$ & 1.59 & $1.02,2.48$ & 1.45 & $0.90,2.34$ & \\
\hline Q4 $(\geq 0.335)$ & 145 & $40 \cdot 4$ & 95 & $25 \cdot 0$ & 2.69 & $1 \cdot 76,4 \cdot 10$ & 2.55 & $1.61,4.06$ & \\
\hline
\end{tabular}

Q, quartile.

* From logistic regression model adjusting for age (years), sex, ethnic group (Han, minority), education level (none/primary, secondary, tertiary), BMl (5 years ago, $\mathrm{kg} / \mathrm{m}^{2}$ ), total energy intake $(\mathrm{kJ} / \mathrm{d}(\mathrm{kcal} / \mathrm{d})$ ), smoking status (never, ever), alcohol drinking (never/seldom, often) and family history of cancer in first-degree relatives (no, yes).

pro-inflammatory diet and oesophageal cancer risk. We also cannot rule out selection bias (i.e. towards healthier cases), as patients who died from oesophageal cancer in the last 12 months were not included in the study. Nevertheless, the use of four hospitals reduced selection bias to some extent, as these hospitals serve the entire catchment region. Therefore, the participants are probably representative of the target population of Xinjiang Uyghur Autonomous Region. Although the recall of habitual food and beverage consumption should not be affected by case-control status, dietary assessment was made on the basis of self-report, which probably introduced some recall error in the response of participants, especially because the recall period of dietary intake was set at 5 years before the interview. Face-to-face interviews were thus conducted in the presence of next-of-kin to help improve the accuracy of their answers ${ }^{(37)}$. Furthermore, information bias was minimised by binding all participants to the study hypothesis; i.e. the idea that pro-inflammatory diets are associated with increased risk of oesophageal cancer in the north-west of China was not commonly held at the time of interview. Alcoholic beverage intake also represents an area of weakness as status was categorised as never/seldom $v$. often, instead of daily intake of alcohol. Because this variable was used in the multivariable logistic regression model, some residual confounding may remain. Finally, information on the histologic subtypes of oesophageal cancer was not available to enable subgroup analyses of oesophageal tumours. However, the vast majority of cancers in this study are, no doubt, ESCC. 


\section{Conclusion}

Consumption of pro-inflammatory diets appears to be associated with an increased risk of oesophageal cancer in Northwestern China. Although further prospective cohort studies are required to confirm the findings, discouraging the intake of more pro-inflammatory foods, such as processed meat and red meat, may be a strategy to protect against oesophageal cancer in this high-risk area of China.

\section{Acknowledgements}

The authors would like to thank nurses for conducting patient interviews. The authors acknowledge patients and their families for their time and willingness to contribute to this study.

N. S. and J. R. H. were supported by grant no. R44DK103377 from the US National Institute of Diabetes and Digestive and Kidney Diseases. The funder did not have any role in the design, analysis or writing of this article.

F. X. and C. W. B. conceived and designed the study; L. T. and N. S. drafted the manuscript; N. S. calculated the DII scores; L. T. and A. H. L. performed the data analysis; and J. R. H., F. X. and C. W. B. provided suggestions and critically revised the manuscript. All the authors have read and approved the final version of the manuscript.

J. R. H. owns controlling interest in Connecting Health Innovations LLC (CHI), a company planning to license the right to his invention of the DII from the University of South Carolina in order to develop computer and smart phone applications for patient counselling and dietary intervention in clinical settings. N. S. is an employee of CHI. The subject matter of this paper will have no direct bearing on the work of $\mathrm{CHI}$, nor has any $\mathrm{CHI}-$ related activity exerted any influence on this project. None of the authors has any conflicts of interest to declare.

\section{References}

1. Torre LA, Bray F, Siegel RL, et al. (2015) Global cancer statistics, 2012. CA Cancer J Clin 65, 87-108.

2. Ferlay J, Soerjomataram I, Dikshit R, et al. (2015) Cancer incidence and mortality worldwide: sources, methods and major patterns in GLOBOCAN 2012. Int J Cancer 136, E359-E386.

3. Pakzad R, Mohammadian-Hafshejani A, Khosravi B, et al. (2016) The incidence and mortality of esophageal cancer and their relationship to development in Asia. Ann Transl Med 4, 29.

4. Ahsan H, Neugut AI \& Gammon MD (1997) Association of adenocarcinoma and squamous cell carcinoma of the esophagus with tobacco-related and other malignancies. Cancer Epidemiol Biomarkers Prev 6, 779-782.

5. Kabat GC, Shivappa N \& Hebert JR (2012) Mentholated cigarettes and smoking-related cancers revisited: an ecologic examination. Regul Toxicol Pharmacol 63, 132-139.

6. Lu Y, Shivappa N, Lin Y, et al. (2016) Diet-related inflammation and oesophageal cancer by histological type: a nationwide case-control study in Sweden. Eur J Nutr 55, $1683-1694$.

7. Zeng H, Zheng R, Zhang S, et al. (2016) Esophageal cancer statistics in China, 2011: estimates based on 177 cancer registries. Thorac Cancer 7, 232-237.
8. Morita M, Kumashiro R, Kubo N, et al. (2010) Alcohol drinking, cigarette smoking, and the development of squamous cell carcinoma of the esophagus: epidemiology, clinical findings, and prevention. Int J Clin Oncol 15, 126-134.

9. World Cancer Research Fund International \& American Institute for Cancer Research (2016) Continuous update project report: diet, nutrition, physical activity and oesophageal cancer. http://www.aicr.org/continuous-update-project/reports/ oesophageal-cancer-cup-report.pdf (accessed November 2017).

10. Keibel A, Singh V \& Sharma MC (2009) Inflammation, microenvironment, and the immune system in cancer progression. Curr Pharm Des 15, 1949-1955.

11. Pan MH, Lai CS, Dushenkov S, et al. (2009) Modulation of inflammatory genes by natural dietary bioactive compounds. J Agric Food Chem 57, 4467-4477.

12. O'Sullivan KE, Phelan JJ, O'Hanlon C, et al. (2014) The role of inflammation in cancer of the esophagus. Expert Rev Gastroenterol Hepatol 8, 746-760.

13. Corley DA, Kerlikowske K, Verma R, et al. (2003) Protective association of aspirin/NSAIDs and esophageal cancer: a systematic review and meta-analysis. Gastroenterology 124, 47-56.

14. de Mello VD, Schwab U, Kolehmainen M, et al. (2011) A diet high in fatty fish, bilberries and wholegrain products improves markers of endothelial function and inflammation in individuals with impaired glucose metabolism in a randomised controlled trial: the Sysdimet study. Diabetologia 54, $2755-2767$.

15. Khoo J, Piantadosi C, Duncan R, et al. (2011) Comparing effects of a low-energy diet and a high-protein low-fat diet on sexual and endothelial function, urinary tract symptoms, and inflammation in obese diabetic men. J Sex Med $\mathbf{8}$, 2868-2875.

16. Luciano M, Mottus R, Starr JM, et al. (2012) Depressive symptoms and diet: their effects on prospective inflammation levels in the elderly. Brain Behav Immun 26, 717-720.

17. Shivappa N, Steck SE, Hurley TG, et al. (2014) Designing and developing a literature-derived, population-based dietary inflammatory index. Public Health Nutr 17, 1689-1696.

18. Lin Y, Yngve A, Lagergren J, et al. (2012) Dietary intake of lignans and risk of adenocarcinoma of the esophagus and gastroesophageal junction. Cancer Causes Control 23, 837-844.

19. Qu X, Ben Q \& Jiang Y (2013) Consumption of red and processed meat and risk for esophageal squamous cell carcinoma based on a meta-analysis. Ann Epidemiol 23, 762-770.e1.

20. Terry P, Lagergren J, Ye W, et al. (2001) Inverse association between intake of cereal fiber and risk of gastric cardia cancer. Gastroenterology 120, 387-391.

21. Wirth MD, Burch J, Shivappa N, et al. (2014) Dietary inflammatory index scores differ by shift work status: NHANES 2005 to 2010. J Occup Environ Med 56, 145-148.

22. Shivappa N, Steck SE, Hurley TG, et al. (2014) A populationbased dietary inflammatory index predicts levels of C-reactive protein in the Seasonal Variation of Blood Cholesterol Study (SEASONS). Public Health Nutr 17, 1825-1833.

23. Shivappa N, Hebert JR, Rietzschel ER, et al. (2015) Associations between dietary inflammatory index and inflammatory markers in the Asklepios Study. Br J Nutr 113, 665-671.

24. Tabung FK, Steck SE, Zhang J, et al. (2015) Construct validation of the dietary inflammatory index among postmenopausal women. Ann Epidemiol 25, 398-405.

25. Zamora-Ros R, Shivappa N, Steck SE, et al. (2015) Dietary inflammatory index and inflammatory gene interactions in relation to colorectal cancer risk in the Bellvitge colorectal cancer case-control study. Genes Nutr 10, 447. 
26. Shivappa N, Zucchetto A, Montella M, et al. (2015) Inflammatory potential of diet and risk of colorectal cancer: a case-control study from Italy. Br J Nutr 114, 152-158.

27. Tabung FK, Steck SE, Ma Y, et al. (2015) The association between dietary inflammatory index and risk of colorectal cancer among postmenopausal women: results from the Women's Health Initiative. Cancer Causes Control 26, 399-408.

28. Wirth MD, Shivappa N, Steck SE, et al. (2015) The dietary inflammatory index is associated with colorectal cancer in the National Institutes of Health-American Association of Retired Persons Diet and Health Study. Br J Nutr 113, 1819-1827.

29. Shivappa N, Prizment AE, Blair CK, et al. (2014) Dietary inflammatory index and risk of colorectal cancer in the Iowa Women's Health Study. Cancer Epidemiol Biomarkers Prev 23, 2383-2392

30. Shivappa N, Bosetti C, Zucchetto A, et al. (2015) Dietary inflammatory index and risk of pancreatic cancer in an Italian case-control study. Br J Nutr 113, 292-298.

31. Shivappa N, Zucchetto A, Serraino D, et al. (2015) Dietary inflammatory index and risk of esophageal squamous cell cancer in a case-control study from Italy. Cancer Causes Control 26, 1439-1447.

32. Shivappa N, Bosetti C, Zucchetto A, et al. (2015) Association between dietary inflammatory index and prostate cancer among Italian men. Br J Nutr 113, 278-283.

33. Shivappa N, Hebert JR, Polesel J, et al. (2016) Inflammatory potential of diet and risk for hepatocellular cancer in a casecontrol study from Italy. Br J Nutr 115, 324-331.

34. Shivappa N, Hebert JR, Anderson LA, et al. (2017) Dietary inflammatory index and risk of reflux oesophagitis, Barrett's oesophagus and oesophageal adenocarcinoma: a populationbased case-control study. Br J Nutr 117, 1323-1331.

35. Zheng S, Vuitton L, Sheyhidin I, et al. (2010) Northwestern China: a place to learn more on oesophageal cancer. Part one: behavioural and environmental risk factors. Eur $J$ Gastroenterol Hepatol 22, 917-925.

36. Garbbert HE, Shimoda T, Hainaut $\mathrm{P}$, et al. (2000) Tumours of the oesophagus. In World Health Organization Classification of Tumours Pathology and Genetics of Tumours of the Digestive System, pp. 9-30 [SR Hamilton and LA Aaltonen, editors]. Lyon: IARC Press.

37. Liang W, Binns C, Lee AH, et al. (2008) The reliability of dietary and lifestyle information obtained from spouses in an elderly Chinese population. Asia Pac J Public Health 20, 87-93.

38. Zhang $\mathrm{T}$ (2010) Investigation on dietary factors and lifestyles of oesophageal cancer patients in Xinjiang. Master's Thesis, Shihezi University.

39. Chinese Center for Disease Control and Prevention (2009) China Food Composition Table, 2nd ed. Beijing: Peking University Medical Press.

40. US Department of Agriculture \& Agricultural Research Service (2016) USDA National Nutrient Database for Standard Reference, Release 28. https://www.ars.usda.gov/northeast-area/ beltsville-md/beltsville-human-nutrition-research-center/ nutrient-data-laboratory/docs/usda-national-nutrient-databasefor-standard-reference/ (accessed March 2017).

41. Liu J, Li Z, Cui J, et al. (2012) Cellular changes in the tumor microenvironment of human esophageal squamous cell carcinomas. Tumour Biol 33, 495-505.

42. Bonomi M, Patsias A, Posner M, et al. (2014) The role of inflammation in head and neck cancer. Adv Exp Med Biol 816, 107-127.

43. Dommels YE, Haring MM, Keestra NG, et al. (2003) The role of cyclooxygenase in $n-6$ and $n-3$ polyunsaturated fatty acid mediated effects on cell proliferation, PGE(2) synthesis and cytotoxicity in human colorectal carcinoma cell lines. Carcinogenesis 24, 385-392.

44. Chung MY, Lim TG \& Lee KW (2013) Molecular mechanisms of chemopreventive phytochemicals against gastroenterological cancer development. World J Gastroenterol 19, 984-993.

45. Fietkau R, Lewitzki V, Kuhnt T, et al. (2013) A disease-specific enteral nutrition formula improves nutritional status and functional performance in patients with head and neck and esophageal cancer undergoing chemoradiotherapy: results of a randomized, controlled, multicenter trial. Cancer 119, 3343-3353.

46. Lin Y, Lagergren J \& Lu Y (2011) Dietary acrylamide intake and risk of esophageal cancer in a population-based casecontrol study in Sweden. Int J Cancer 128, 676-681.

47. De Groot KM (2006) Cancer of the oesophagus - quo vadis? S Afr Med J 96, 197-198.

48. Terry PD, Lagergren J, Wolk A, et al. (2003) Dietary intake of heterocyclic amines and cancers of the esophagus and gastric cardia. Cancer Epidemiol Biomarkers Prev 12, 940-944.

49. Groblewska M, Mroczko B, Sosnowska D, et al. (2012) Interleukin 6 and C-reactive protein in esophageal cancer. Clin Chim Acta 413, 1583-1590.

50. Blank S, Nienhuser H, Dreikhausen L, et al. (2017) Inflammatory cytokines are associated with response and prognosis in patients with esophageal cancer. Oncotarget $\mathbf{8}$, 47518-47532.

51. Lambert R, Hainaut P \& Parkin DM (2004) Premalignant lesions of the esophagogastric mucosa. Semin Oncol 31, 498-512.

52. Shivappa N, Hebert JR \& Rashidkhani B (2015) Dietary inflammatory index and risk of esophageal squamous cell cancer in a case-control study from Iran. Nutr Cancer 67, $1253-1259$

53. Colleypriest BJ, Ward SG \& Tosh D (2009) How does inflammation cause Barrett's metaplasia? Curr Opin Pharmacol 9, 721-726.

54. Drahos J, Li L, Jick SS, et al. (2016) Metabolic syndrome in relation to Barrett's esophagus and esophageal adenocarcinoma: Results from a large population-based case-control study in the Clinical Practice Research Datalink. Cancer Epidemiol 42, 9-14.

55. Kavanagh ME, O'Sullivan KE, O'Hanlon C, et al. (2014) The esophagitis to adenocarcinoma sequence; the role of inflammation. Cancer Lett 345, 182-189.

56. Song JH, Han YM, Kim WH, et al. (2016) Oxidative stress from reflux esophagitis to esophageal cancer: the alleviation with antioxidants. Free Radic Res 50, 1071-1079.

57. Maghsudlu M \& Farashahi Yazd E (2017) Heat-induced inflammation and its role in esophageal cancer. J Dig Dis 18, 431-444.

58. Tang WR, Chen ZJ, Lin K, et al. (2015) Development of esophageal cancer in Chaoshan region, China: association with environmental, genetic and cultural factors. Int J Hyg Environ Health 218, 12-18.

59. Fang J, Chu L, Li C, et al. (2015) JAK2 inhibitor blocks the inflammation and growth of esophageal squamous cell carcinoma in vitro through the JAK/STAT3 pathway. Oncol Rep 33, 494-502.

60. Diakowska D (2013) Cytokines association with clinical and pathological changes in esophageal squamous cell carcinoma. Dis Markers 35, 883-893.

61. Neto AG, Whitaker A \& Pei Z (2016) Microbiome and potential targets for chemoprevention of esophageal adenocarcinoma. Semin Oncol 43, 86-96. 